\title{
Impact of Porpoise Oil on Selective Biomarkers Associated with Oxidative Stress in Obesity-Induced in Rats
}

\author{
Samia A. Aldardery*, Ayman A.Wagih*, Hanaa H. GabAllah*, \\ Mona A. Abdelazeem** \\ Departments, of Medical Biochemistry*, Histopathology \\ ** Faculty of Medicine, Tanta University, Egypt
}

\begin{abstract}
Background: Porpoise oil is yellow fatty oil obtained from porpoises. It causes a relative improvement of antioxidative defense via antioxidant enzymatic and non enzymatic mechanisms. The antioxidant role of porpoise oil is relevant to its constitution of lipid lowering effects of $\omega-3$ polyunsaturated fatty acids) (PUFAs). Obesity has become a leading global health problem owing to its strong association with a high incidence of diseases. Oxidative stress may play a critical role in the pathogenesis and development of obesity-related diseases. Aim of the work: The aim of the present study was to evaluate the possible mechanisms of obesity-induced oxidative stress and to determine the efficacy of porpoise oil on counteracting oxidative stress induced by obesity in rats. Materials and methods: The study was carried out on 75 female albino rats which were divided into 5 groups each comprise 15 rats: group I (control non obese), group II (control obese), group III (non obese with porpoise oil administration), group IV (porpoise oil administration with induction of obesity) and group $V$ (porpoise oil administration after induction of obesity). All groups were subjected to estimation of plasma lipid profile, plasma xanthine oxidase activity, total antioxidant capacity (TAC), hydrogen peroxide level $\left(\mathrm{H}_{2} \mathrm{O}_{2}\right)$, and malondialdehyde level $(\mathrm{MDA})$. Liver specimens were taken for histopathological examination. Results: The present study confirmed a state of dyslipidemia in obese rats manifested by significantly higher plasma levels of total triglycerides, total cholesterol, LDL-cholesterol and low levels of HDL-cholesterol as compared to the control rats. There was significant increase in $M D A$ as well as, $\mathrm{H}_{2} \mathrm{O}_{2}$ levels, and xanthine oxidase activity, with significant decrease in total antioxidant capacity in control obese group as compared to the other groups. Porpoise oil treated group showed significant decrease in plasma levels of $\mathrm{MDA}, \mathrm{H}_{2} \mathrm{O}_{2}$, xanthine oxidase activity, with significant increase in TAC. Also, an improvement in lipid profile and lobular architecture of the liver occurred with porpoise oil administration.

Conclusion: From these results it could be concluded that obesity is a state of chronic oxidative stress and may be an inductive factor of several biochemical, metabolic alterations and also hepatic histopathological changes. Porpoise oil significantly improves the biochemical, metabolic and histopathological abnormalities induced by obesity due to its powerful lipid lowering and antiinflammatory effects and unique antioxidant properties.
\end{abstract}




\section{INTRODUCTION}

Obesity is a pathological condition in which excess body fat has accumulated to the extent that it may have an adverse effect on health leading to reduced life expectancy and/or increased health problems ${ }^{(1)}$. The great similarity and homology between the genomes of rodents and humans make these animal models a major tool to study obesity ${ }^{(2)}$.

Obesity is associated with an increased risk of nonalcoholic fatty liver disease (NAFLD) ${ }^{(3)}$. Steatosis, the hallmark feature of NAFLD, occurs when the rate of hepatic fatty acid uptake from plasma and de novo fatty acid synthesis is greater than the rate of fatty acid oxidation and export $^{(4)}$

Reactive oxygen species (ROS) are generated as a result of normal metabolic processes in the cell, including the uncoupling of the electron transport chain in the mitochondria and the oxidation of excess NADPH by NADPH oxidase (5). Accumulation of ROS in the body is highly correlated with obesity due to generation of these radicals from fat accumulation $^{(6)}$.

Xanthine oxidase (XO) is an enzyme that generates reactive oxygen species ${ }^{(7) .}$ It is a superoxide-producing enzyme found normally in the vascular endothelium ${ }^{(8)}$. It catalyzes the oxidation of hypoxanthine to xanthine then to uric acid ${ }^{(9)}$.

Hydrogen peroxide $\left(\mathrm{H}_{2} \mathrm{O}_{2}\right)$ is a non-radical species primarily produced during the dismutation of superoxide anion via superoxide dismutase (SOD); and directly by several oxidases (e.g., glycolate oxidase, xanthine oxidase) ${ }^{(10)}$.

Oxidative stress (OS) is associated with cumulative body damage caused by free radicals inadequately neutralized by antioxidants $^{(11)}$. Oxidative stress induces cell injury through the oxidative damage of lipid, protein and $\mathrm{DNA}^{(12)}$.

MDA is an end product of lipid peroxidation produced during the oxidative breakdown of lipids (13). Measurement of MDA is an indicator of oxidative damage to cells and tissue and an indirect index of ROS $\operatorname{activity}^{(14)}$.

Determination of total antioxidant capacity (TAC) is a tool in medical diagnosis and treatment of several diseases. In plasma, antioxidant molecules involved in free radical scavenging include endogenous (e.g. uric acid, albumin and circulating thiols) and exogenous (e.g. vitamins E and C) antioxidant molecules ${ }^{(15)}$.

TAC considers the sum action of all the endogenous and exogenousderived antioxidants present in plasma and body fluids and provides an integrated parameter rather than the simple sum of measurable antioxidants ${ }^{(\mathbf{1 6})}$. It has been suggested that plasma TAC levels modified during oxidative stress conditions ${ }^{(15)}$.

Porpoise oil is also known as dolphin oil, is pale yellow fatty oil extracted from porpoise adipose tissue by evaporation process. The tissues of porpoise contain combination of isovaleric acid and omega 3 polyunsaturated fatty acids ( $\omega 3$ PUFAS) ${ }^{(\mathbf{1 7}) . \quad \text { Administration of }}$ porpoise oil was noted to act through the enhancement of lipoprotein 
secretion and to increase adiponectin production in experimental animals $^{(17)}$.

AIM OF WORK: The present work aimed to evaluate the possible mechanisms of obesity-induced oxidative stress and to determine the efficacy of porpoise oil on counteracting obesity-induced oxidative stress in rats.

\section{MATERIALS \& METHODS}

The study was carried out on 75 female albino rats of $120-150 \mathrm{~g}$ body weight. During the study the animals were kept in wire mesh cages, room temperature was $22-24{ }^{\circ} \mathrm{C}$, the animals were exposed to 12:12 hours light dark cycles, allowed free access to water and to either a control diet or high-fat diet.

Experimental design: The studied animals were divided randomly into five groups, each comprise 15 rats:

1. Group I (control non obese): rats fed on normal caloric diet for 8 weeks.

2. Group II (control obese): rats received high fat diet for 8 weeks.

3. Group III (non obese with porpoise oil administration): non obese rats fed normal caloric diet with simultaneous administration of porpoise oil in a dose of $1 \mathrm{ml} / \mathrm{Kg}$. orally for 8 weeks.

4. Group IV (porpoise oil administered with obesity induction): rats fed high fat diet with simultaneous administration of porpoise oil in a dose of $1 \mathrm{ml} / \mathrm{Kg}$. orally for 8 weeks.

5. Group V (porpoise oil administration after obesity induction): rats fed high fat diet for 6 weeks then administration of porpoise oil in a dose of $1 \mathrm{ml} / \mathrm{Kg}$. orally for 2 weeks.

Blood Sampling: After fasting for 12 hours the animals were anaesthetized by ether, and while the heart is still beating $3 \mathrm{ml}$ of blood were collected via cardiac puncture on heparin, samples centrifuged and the plasma was separated, divided into aliquots and frozen at $-70 \mathrm{C}^{\mathbf{0}}$ till used.

All groups were subjected to plasma measurement of plasma xanthine oxidase activity ${ }^{(\mathbf{1 8})}$ : total antioxidant capacity ${ }^{(\mathbf{1 9})}$, hydrogen peroxide ${ }^{(20)}$, malondialdehyde (MDA) level ${ }^{(21,22)}$ : and Lipid profile including triacylglycerol (TAG) (23), total cholesterol (TC) level ${ }^{(24)}$, high density lipoprotein cholesterol (HDL-C) (25) and low density lipoprotein cholesterol (LDL-C) level ${ }^{\text {(26) }}$

\section{RESULTS}

Table (1) showed a significant increase of total body weight in group II compared to group I, group III, group IV and group V ( $\mathrm{P}$ value $<0.05)$. Also, there was significant increase in group II (Control obese) compared to group V $(\mathrm{P}$ value $<0.05)$

Table (2) showed significant increase of visceral fat weight in control obese group compared to the other groups $(\mathrm{P}<0.001)$.

Figure $(1,2)$ showed comparison between weight gain (g.) of the studied groups throughout the experimental study, starting from the initial weight at 0 week to weight at 8 weeks, each separated by one week interval. ANOVA test shows significant differences between the studied groups (F values were 3.256, 
$3.147,10.253,7.253,4.639,10.253$, $5.663,9.263$, and 7.362 respectively, $\mathrm{P}<0.05$ ).

Table (3) showed significant increase of xanthine oxidase activity in group II compared to group I, group III, group IV and group $\mathrm{V}(\mathrm{P}<0.05)$. Significant lower values were detected in group IV as compared to the other groups.

Total anti oxidant capacity showed significant increase in group III and group IV compared to group I, group II and Group V $(\mathrm{P}<0.05)$ as illustrated in Table (4). It also showed significant decrease in group II compared to the other groups.

Also, both $\mathrm{H}_{2} \mathrm{O}_{2}$ and MDA plasma levels showed significant increase in group II compared to the other groups $(\mathrm{P}<0.05)$. Significant lower values were detected in group IV as illustrated in Tables 5\&6.

Table (7) showed a state of dyslipidemia in group II, with significant increase of plasma TAG, TC and LDL-c compared to group I, group III, group IV and group $\mathrm{V}(\mathrm{P}<$ 0.05) Significant decrease of serum HDL-C level was also detected in group II as compared to the other groups $\quad(\mathrm{P}<0.001) . \quad$ Significant improvement in lipid profile was detected with porpoise oil administration.

Correlation studies showed significant negative correlation in group II between total body weight and TAC $(r=-0.536 \& \mathrm{P}<0.05)$ and significant positive correlation between $\mathrm{H}_{2} \mathrm{O}_{2}$ levels $\quad(\mathrm{r}=0.706 \quad$ \& $\mathrm{P}<0.05)$, MDA levels $\quad(\mathrm{r}=0.430 \quad \&$ $\mathrm{P}<0.05)$, xanthine oxidase activity $(\mathrm{r}=0.210$ \& $\mathrm{P}<0.05$ as illustrated in Table 8 .

Significant negative correlation was found in group IV between total body weight of rats with TAC ( $\mathrm{r}=$ $0.912 \& \quad \mathrm{P}<0.05)$ and significant positive correlation between $\mathrm{H}_{2} \mathrm{O}_{2}$ levels $(\mathrm{r}=0.881 \& \mathrm{P}$-value $<0.05)$, MDA levels $(r=0.858 \& \mathrm{P}<0.05)$, xanthine oxidase activity $(\mathrm{r}=0.868 \& \mathrm{P}<0.05)$ as illustrated in table 9.

Also, negative correlation was found in group $\mathrm{V}$ between total body weight of rats with TAC $(\mathrm{r}=$ $0.862 \& \mathrm{P}<0.05)$ and significant positive correlation between $\mathrm{H}_{2} \mathrm{O}_{2}$ levels $\quad(\mathrm{r}=0.459 \quad \& \quad \mathrm{P}<0.05), \quad \mathrm{MDA}$ levels $\quad(\mathrm{r}=0.257 \quad \& \quad \mathrm{P}<0.05), \quad \mathrm{XO}$ activity $\quad(\mathrm{r}=0.020 \quad \& \quad \mathrm{P}<0.05) \quad$ as illustrated in table 10 .

Histopathological results in the present study showed no changes in the histological appearance of the livers of the rats from group I (control non obese) normal lobular architecture of liver with normal hepatocytes, as shown in Fig 1. Liver of rats from group II (control obese) showed excessive steatosis (fatty change) of hepatocytes Fig1I. Liver of rats from group III showed normal lobular architecture of liver with normal hepatocytes with noticeable histopathological changes could be seen as shown in Fig 1II. Liver of rats from group IV showed normal lobular architecture with few hepatocytes showing fatty change and mild inflammatory infiltrate seen as shown in Fig1V. Group V showed many hepatocytes with fatty change more than those observed in previous figure with mild inflammatory infiltrate. 
Table 1: Total body weight of rats (g.) of the studied groups.

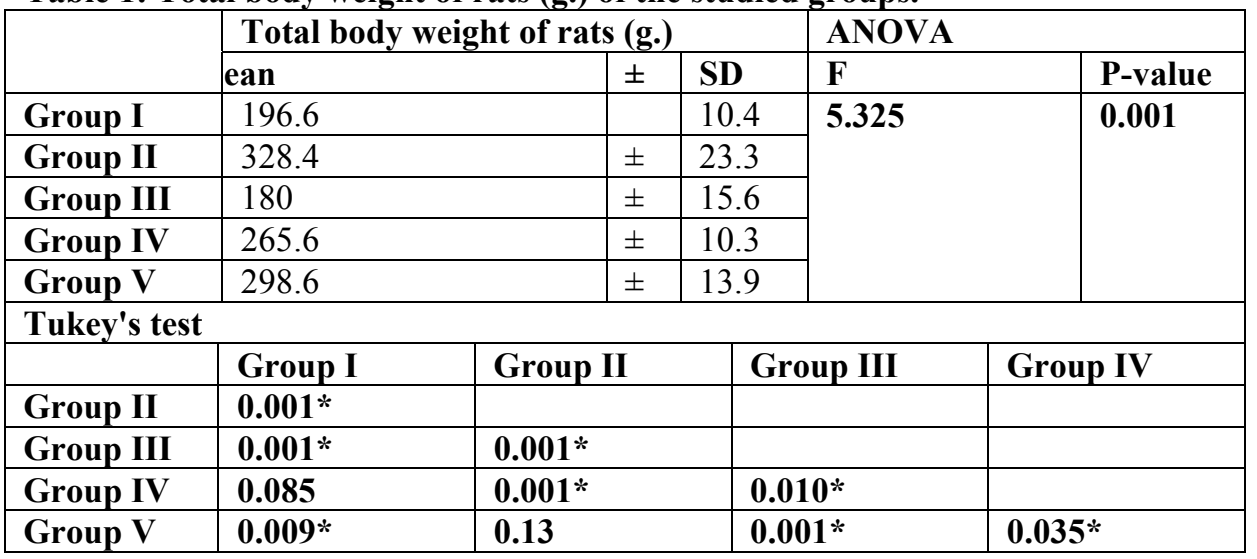

Group I: Control non obese. Group II: Control obese.

Group III: Non obese with porpoise oil administration.

Group IV: Porpoise oil administration with obesity induction.

Group V: Porpoise oil administration after obesity induction.

Table 2: weight of visceral fat (g.) of the studied groups $(n=15$ rats in each group).

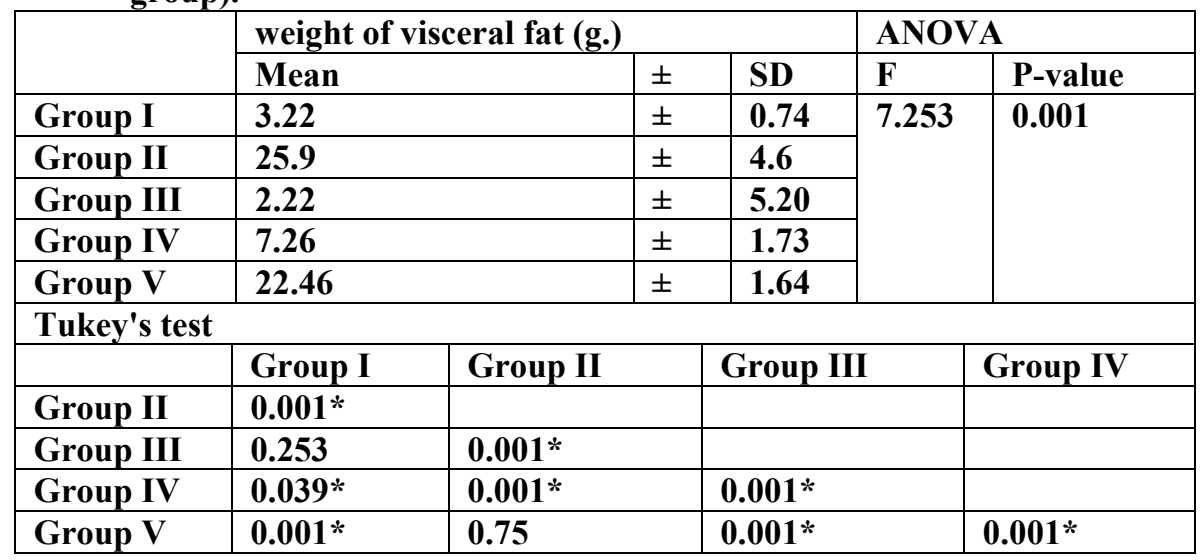

Group I: Control non obese. Group II: Control obese.

Group III: Non obese rats with porpoise oil administration.

Group IV: Porpoise oil administered with obesity induction.

Group V: Porpoise oil administered after obesity induction. 


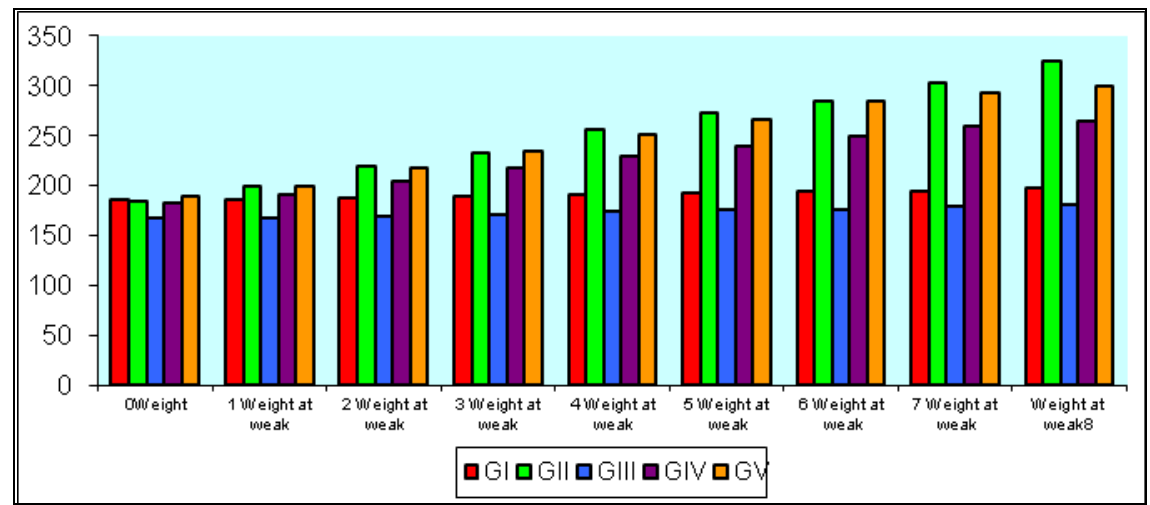

Fig.1: Comparison between the studied groups as regards weight gain (gm) throughout the experimental study starting from the initial weight at 0 week to weight at 8 weeks.

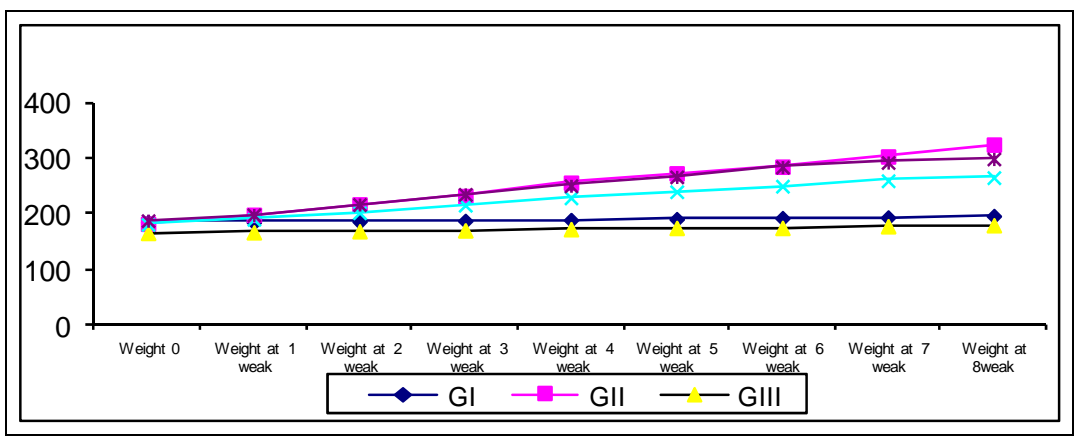

Fig.2: Comparison between the studied groups as regards weight gain (gm) throughout the experimental study starting from the initial weight at 0 week to weight at 8 weeks. 
Table 3: Xanthine oxidase activity $(\mathrm{U} / \mathrm{ml}$.) of the studied groups. $(\mathrm{n}=15$ rats in each group).

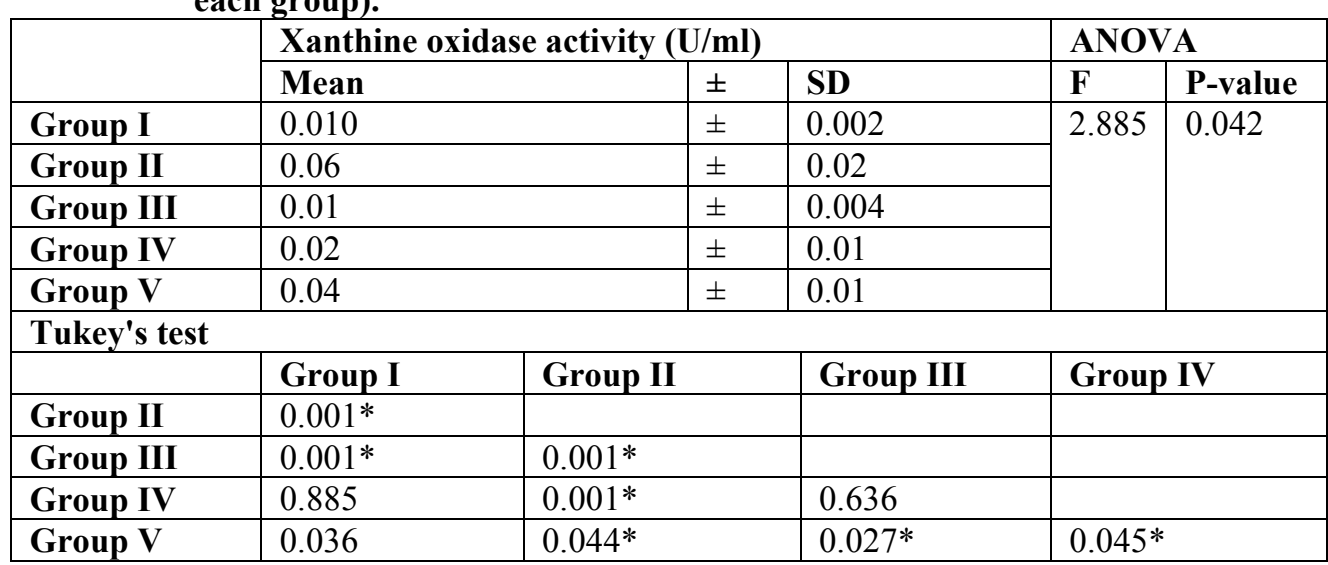

Group I: Control non obese.

Group II: Control obese.

Group III: Non obese rats with porpoise oil administration.

Group IV: Porpoise oil administered with obesity induction.

Group V: Porpoise oil administered after obesity induction.

Table4: Total anti oxidant capacity $(\mathrm{mM} / \mathrm{l}$.$) of the studied groups (\mathrm{n}=15$ rats in each group)..

\begin{tabular}{|c|c|c|c|c|c|c|}
\hline & \multicolumn{4}{|c|}{ Total anti oxidant capacity $(\mathrm{mM} / \mathrm{l})$} & \multicolumn{2}{|c|}{ ANOVA } \\
\hline & \multicolumn{2}{|l|}{ Mean } & \pm & SD & $\mathbf{F}$ & P-value \\
\hline Group I & \multicolumn{2}{|l|}{1.68} & \pm & 0.21 & \multirow[t]{5}{*}{4.639} & \multirow[t]{5}{*}{$0.002 *$} \\
\hline Group II & \multicolumn{2}{|l|}{0.73} & \pm & 0.15 & & \\
\hline Group & \multicolumn{2}{|l|}{1.99} & \pm & 0.28 & & \\
\hline Group & \multicolumn{2}{|l|}{1.76} & \pm & 0.15 & & \\
\hline Group V & \multicolumn{2}{|l|}{1.44} & \pm & 0.08 & & \\
\hline \multicolumn{7}{|c|}{ Tukey's test } \\
\hline & Group I & Group II & \multicolumn{2}{|r|}{ Group III } & \multicolumn{2}{|c|}{ Group IV } \\
\hline Group II & $0.001^{*}$ & & & & & \\
\hline Group & $0.036^{*}$ & $0.001 *$ & & & & \\
\hline Group & 0.255 & $0.001 *$ & & .088 & & \\
\hline Group V & $0.021 *$ & $0.009^{*}$ & & $.033 *$ & & \\
\hline
\end{tabular}

Group I: Control non obese.

Group II: Control obese.

Group III: Non obese rats with porpoise oil administration.

Group IV: Porpoise oil administered with obesity induction.

Group V: Porpoise oil administered after obesity induction. 
Table 5: Hydrogen peroxide level $(\mu M / l$.$) of the studied groups (n=15$ rats in each group).

\begin{tabular}{|c|c|c|c|c|c|c|}
\hline & \multicolumn{4}{|c|}{ Hydrogen peroxide level ( $\mu \mathrm{M} / \mathrm{l})}$. & \multicolumn{2}{|c|}{ ANOVA } \\
\hline & \multicolumn{2}{|l|}{ Mean } & \pm & SD & $\mathbf{F}$ & P-value \\
\hline Group I & \multicolumn{2}{|l|}{0.05} & \pm & 0.04 & \multirow[t]{5}{*}{3.639} & \multirow[t]{5}{*}{$0.019^{*}$} \\
\hline Group II & \multicolumn{2}{|l|}{0.08} & \pm & 0.16 & & \\
\hline Group III & \multicolumn{2}{|l|}{0.03} & \pm & 0.01 & & \\
\hline Group IV & \multicolumn{2}{|l|}{0.06} & \pm & 0.01 & & \\
\hline Group V & \multicolumn{2}{|l|}{0.07} & \pm & 0.31 & & \\
\hline \multicolumn{7}{|c|}{ Tukey's test } \\
\hline & Group I & \multicolumn{2}{|l|}{ Group II } & \multicolumn{2}{|l|}{ Group III } & Group IV \\
\hline Group II & $0.001 *$ & & & & & \\
\hline Group III & $0.002 *$ & $0.001 *$ & & & & \\
\hline Group IV & 0.053 & $0.008 *$ & & $0.025^{*}$ & & \\
\hline Group V & $0.006^{*}$ & $0.001^{*}$ & & $0.001 *$ & & \\
\hline
\end{tabular}

Group I: Control non obese. Group II: Control obese.

Group III: Non obese rats with porpoise oil administration.

Group IV: Porpoise oil administered with obesity induction.

Group V: Porpoise oil administered after obesity induction.

Table 6: Malondialdehyde level (nmol/l.) of the studied groups $(n=15$ rats in each group).

\begin{tabular}{|c|c|c|c|c|c|c|}
\hline \multirow[t]{2}{*}{-} & \multicolumn{4}{|c|}{ Malondialdehyde level (nmol/l.) } & \multicolumn{2}{|c|}{ ANOVA } \\
\hline & \multicolumn{2}{|l|}{ Mean } & \pm & SD & $\mathbf{F}$ & P-value \\
\hline Group I & \multicolumn{2}{|l|}{8.06} & \pm & 0.68 & \multirow[t]{5}{*}{3.256} & \multirow[t]{5}{*}{$0.014 *$} \\
\hline Group II & \multicolumn{2}{|l|}{13.1} & \pm & 0.77 & & \\
\hline Group III & \multicolumn{2}{|l|}{6.51} & \pm & 0.97 & & \\
\hline Group IV & \multicolumn{2}{|l|}{10.80} & \pm & 0.56 & & \\
\hline Group V & \multicolumn{2}{|l|}{12.10} & \pm & 0.37 & & \\
\hline \multicolumn{7}{|c|}{ Tukey's test } \\
\hline & Group I & \multicolumn{2}{|l|}{ Group II } & Group III & & Group IV \\
\hline Group II & $0.002 *$ & & & & & \\
\hline Group & 0.086 & \multicolumn{2}{|l|}{$0.001 *$} & & & \\
\hline Group & 0.085 & \multicolumn{2}{|l|}{$0.042^{*}$} & $0.017^{*}$ & & \\
\hline Group V & $0.023^{*}$ & $0.001 *$ & & $0.001^{*}$ & & 0.360 \\
\hline
\end{tabular}

Group I: Control non obese. Group II: Control obese.

Group III: Non obese rats with porpoise oil administration.

Group IV: Porpoise oil administered with obesity induction.

Group V: Porpoise oil administered after obesity induction. 
Table 7: Statistical comparison between the studied groups $(n=15$ rats in each group)

\begin{tabular}{|l|l|l|l|l|l|l|}
\hline & GI & GII & GIII & GIV & GV & $\begin{array}{l}\text { p. } \\
\text { value }\end{array}$ \\
\hline $\begin{array}{l}\text { Total cholesterol } \\
\text { (mg/dl) }\end{array}$ & $94.10+12.10$ & $161.50+7.08$ & $64.20+4.90$ & $107.40+9.22$ & $142.10+6.10$ & $\mathbf{0 . 0 0 1}$ \\
\hline $\begin{array}{l}\text { Triacylglycerol } \\
\text { (mg/dl) }\end{array}$ & $56.80+2.37$ & $107.6+11.9$ & $45.90+2.51$ & $80.8+6.1$ & $91.9+6.2$ & $\mathbf{0 . 0 0 1}$ \\
\hline $\begin{array}{l}\text { High density } \\
\text { lipoprotein } \\
\text { (mg/dl) }\end{array}$ & $25.50+3.09$ & $35.50+2.83$ & $29.30+3.26$ & $45.30+2.89$ & $35.90+2.32$ & $\mathbf{0 . 0 0 1}$ \\
\hline $\begin{array}{l}\text { Low density } \\
\text { lipoprotein } \\
\text { (mg/dl) }\end{array}$ & $57.20+14.10$ & $104.60+7.65$ & $25.60+7.010$ & $45.80+10.70$ & $87.70+6.90$ & $\mathbf{0 . 0 0 1}$ \\
\hline
\end{tabular}

Group I: Control non obese.

Group II: Control obese.

Group III: Non obese rats with porpoise oil administration.

Group IV: Porpoise oil administered with obesity induction.

Group V: Porpoise oil administered after obesity induction.

Table 8: Correlation matrix between total body weight of rats (gm), total anti oxidant capacity $(\mathrm{mM} / \mathrm{l}$.$) , hydrogen peroxide level (\mu \mathrm{M} / \mathrm{l}$.$) ,$ malondialdehyde level (nmol/l.), xanthine oxidase activities $(\mathrm{U} / \mathrm{ml}$.) in group II .

\begin{tabular}{|l|l|l|}
\hline \multirow{2}{*}{ GII } & \multicolumn{2}{|l|}{ Total body weight of rats (g.) } \\
\cline { 2 - 3 } & r. & p. value \\
\hline Total anti oxidant capacity $(\mathbf{m M} / \mathbf{l})$. & -0.536 & $<0.05^{*}$ \\
\hline Hydrogen peroxide level $(\boldsymbol{\mu M} / \mathbf{l}))$. & 0.706 & $<0.05^{*}$ \\
\hline Malondialdehyde level $(\mathbf{n m o l} / \mathbf{l})$ ) & 0.430 & $<0.05^{*}$ \\
\hline Xanthine oxidase activity $(\mathbf{U} / \mathbf{m} \mathbf{l}))$. & 0.210 & $<0.05^{*}$ \\
\hline
\end{tabular}

Table 9: Correlation matrix between total body weight of rats (g.), total antioxidant capacity (mM./l.), $\mathrm{H}_{2} \mathrm{O}_{2}$ levels $(\mu \mathrm{M} / \mathrm{l}$.), malondialdehyde levels (nM/.l.), xanthine oxidase activities $(\mathrm{U} / \mathrm{ml}$.) in group IV.

\begin{tabular}{|l|l|l|}
\hline \multirow{2}{*}{ GIV } & \multicolumn{2}{|l|}{ Total body weight of rats $(\mathbf{g m})$} \\
\cline { 2 - 3 } & r. & p. value \\
\hline Total anti oxidant capacity $(\mathbf{m M} / \mathbf{l}))$. & -0.912 & $<0.05^{n}$ \\
\hline Hydrogen peroxide level $(\boldsymbol{\mu M} / \mathbf{l}))$. & 0.881 & $<0.05^{n}$ \\
\hline Malondialdehyde level $(\mathbf{n m o l} / \mathbf{l}))$. & 0.858 & $<0.05^{n}$ \\
\hline Xanthine oxidase activity $(\mathbf{U} / \mathbf{m} \mathbf{l}))$. & 0.868 & $<0.05^{n}$ \\
\hline
\end{tabular}

Table 10: Correlation matrix between total body weight of rats (g.), total antioxidant capacity (mM./l.), $\mathrm{H}_{2} \mathrm{O}_{2}$ levels $(\mu \mathrm{M} / \mathrm{l}$.), malondialdehyde levels (nM/.l.), xanthine oxidase activities (U/ml.) in group $\mathrm{V}$.

\begin{tabular}{|l|l|l|}
\hline \multirow{2}{*}{ group V } & \multicolumn{1}{|l|}{ Total body weight of rats (gm) } \\
\hline Total anti oxidant capacity $(\mathbf{m M} / \mathbf{l})$. & -0.862 & p. value \\
\hline Hydrogen peroxide level $(\boldsymbol{\mu M} / \mathbf{l})$. & 0.459 & $<0.05^{\circ}$ \\
\hline Malondialdehyde level $(\mathbf{n m o l} / \mathbf{l})$. & 0.257 & $<0.05^{\circ}$ \\
\hline Xanthine oxidase activity (U/ml.) & 0.020 & $<0.05^{\circ}$ \\
\hline
\end{tabular}




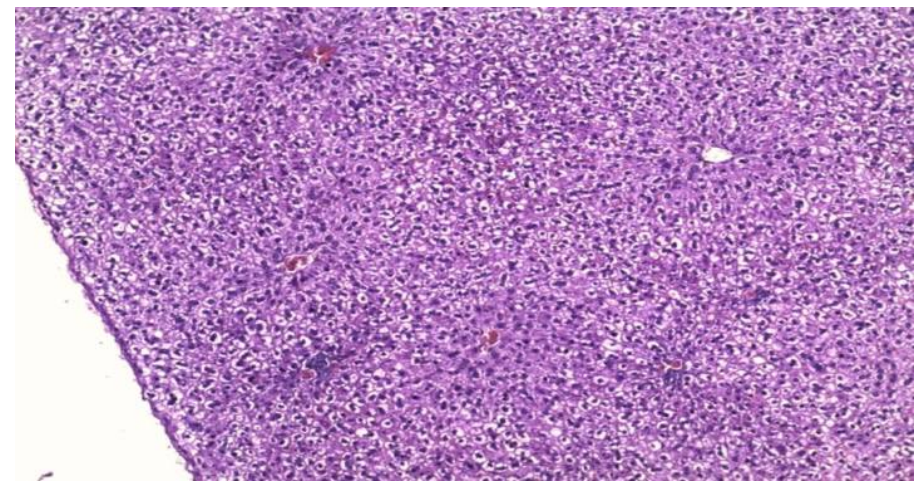

Figure I: shows liver of rats of group II (control obese) where there is excessive steatosis (fatty change) of hepatocytes.

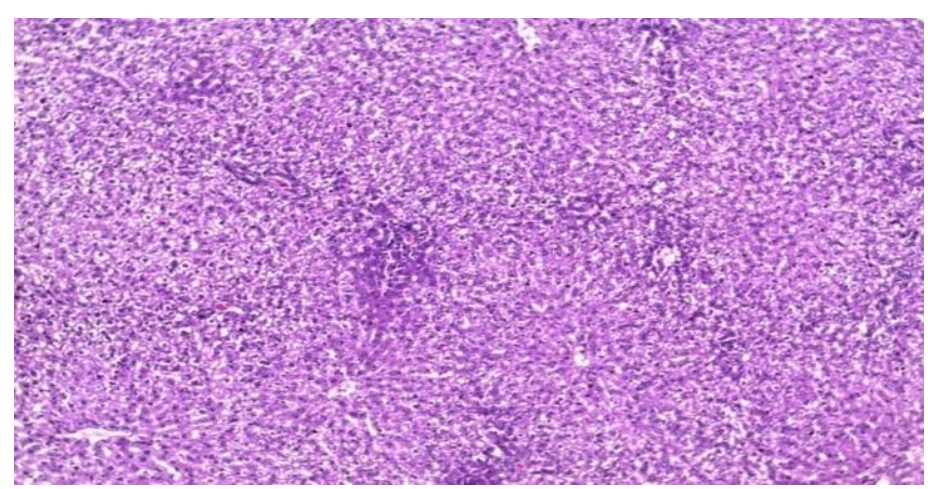

Figure II: shows liver of rats of group II (control obese) where there is excessive steatosis (fatty change) of.

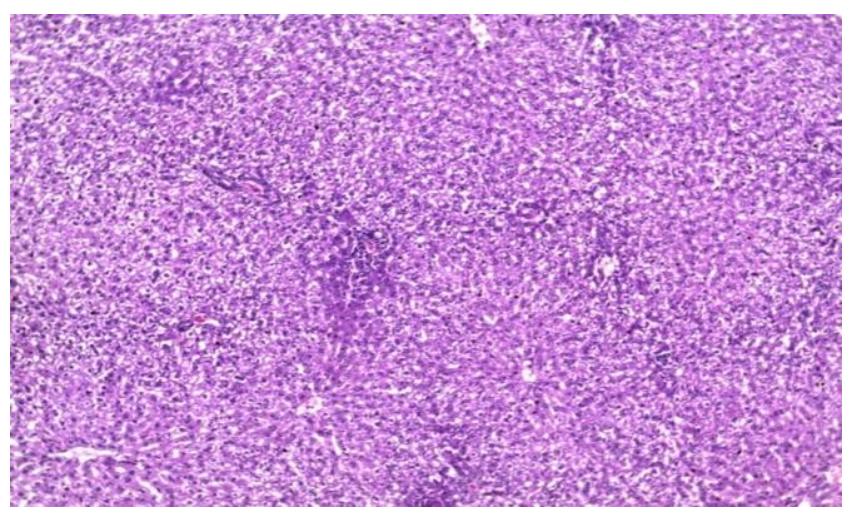

Figure III: shows normal lobular architecture of liver of rats of group III (non obese rats with porpoise oil administration) with normal hepatocytes. No noticeable histopathological changes could be seen. 


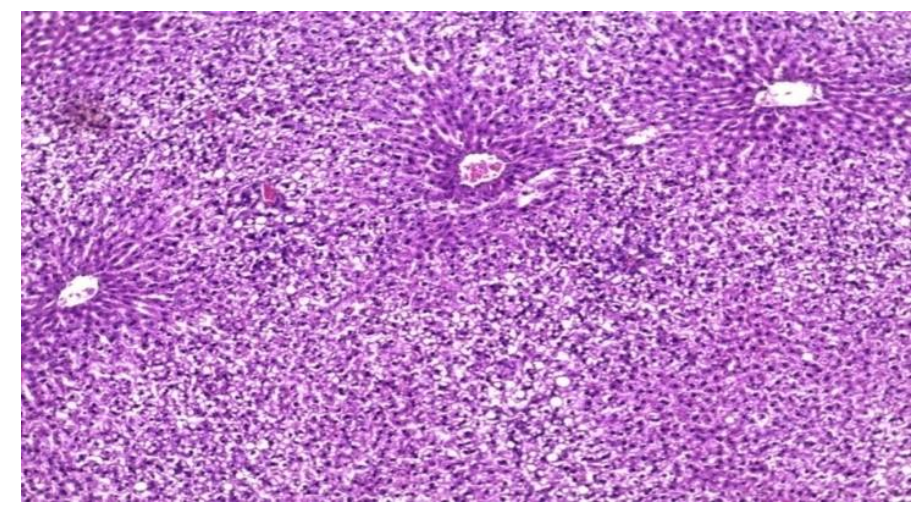

Figure IV: shows normal lobular architecture of liver of rats of group IV (porpoise oil administration with induction of obesity) with few hepatocytes showing fatty change and mild inflammatory infiltrate

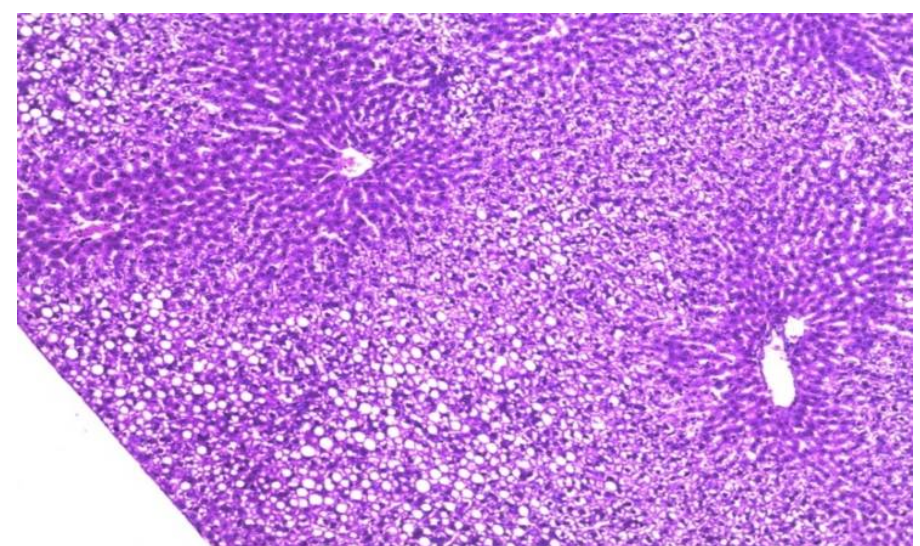

Figure V: shows many hepatocytes of liver of rats of group V(porpoise oil administration after induction of obesity) with fatty change more than those observed in previous figure with mild inflammatory infiltrate

\section{DISCUSSION}

Obesity and systemic oxidative stress are closely related, which supports the notion that a cooperative interaction exists between oxidative stress-induced dysregulation of lipid metabolism and signaling pathways inducing inflammation. Aligning with the magnitude of oxidative stress evident in HFD induced obesity, the monitored reduction of total antioxidant capacity (TAC) and dyslipidemia may coincide as with consequent endothelial dysfunction ${ }^{(27)}$.

This was verified herein by the increased ROS generation via monitored increase of $\mathrm{H}_{2} \mathrm{O}_{2}$ versus decrease of TAC paralleled by the increased end product of lipid 
peroxidation $\mathrm{MDA}^{(\mathbf{2 8 )})}$ Probably, the decreasing activity of cytoprotective enzymes with HFD-induced obesity leads to increased lipid peroxidation product MDA. This initiates a progressive and cumulative cell injury (29). The increased lipid peroxidation leads to inactivation of the enzymes by cross- linking with MDA; this will cause an increased accumulation of superoxide, $\mathrm{H}_{2} \mathrm{O}_{2}$ and hydroxyl radicals which could further stimulates lipid peroxidation ${ }^{(30)}$.

Concordantly, the evaluated MDA increments with hypercholesterolemia herein align with in vitro fatty acid enrichment of macrophage which was reported to alter inflammatory response and net cholesterol accumulation ${ }^{(31)}$. Also, the associated hypertriglyceridemia seen in obese HFD-rats herein may contribute to the alteration in the oxidant-antioxidant balance; suggesting that an increase in the bioavailability of free fatty acids can increase lipid peroxidation ${ }^{(32)}$. In harmony, ROS and lipid peroxidation products which impair the respiratory chain in hepatocytes are also known to activate satellite cells, thus resulting in fibrosis. Such an aspect may align with inflammatory foci that were evidenced with the histopathological findings of fatty liver associated with the obesity-induced HFD in rats ${ }^{(33)}$.

Conversely, its reversion by porpoise oil supplements could occur by sparing the lypophilic antioxidant content of lipoproteins and ultimately by increasing the plasma TAC availability $^{(34)}$. Conceivably, the potential relationship of antioxidative impact of porpoise oil supplementation contributing to readjusting TAC decremental values with adiposity reflects the outcome of counteracting dyslipidemia and associated insulin resistance potentiated by oxidative stress impairment or altered antioxidant status. Consistently, previous reports identified an inverse and independent association between dietary TAC values and oxidizes LDL (OX-LDL), which represents a recognized oxidative stress marker imposing a risk factor for cardiovascular diseases (CVD) ${ }^{(17)}$

In obesity, macrophages in visceral fat increases, so TNF- $\alpha$ production increases, then adiponectin decreases which favor developing insulin resistance ${ }^{(35)}$. In obesity, also, monocyte subfraction is increased, and neutrophil subfraction tends to increase. In consequence, the alleged increased neutrophils could generate superoxide anion via NADPH oxidase with other available ROS intermediates such as $\mathrm{H}_{2} \mathrm{O}_{2}{ }^{\left({ }^{(36)} \text {. }\right.}$

The increased cytokine profile developing alongside a prooxidant status which is provoked by HFD in rats was monitored by decreased TAC herein $^{(37)}$. It may develop relative to increased consumption of endogenous antioxidant defense mechanisms against free radical generation. That pattern was re-shifted towards a balanced prooxidant-antioxidant state by porpoise oil supplementation as evidenced herein ${ }^{(38)}$.

The reduced TAC reflecting response to that elevated oxidative stress has been reported elsewhere in obese subjects to coincide with higher circulating levels of ox-LDL which may align with increased MDA noted in HFD- rats ${ }^{(39) .}$ This could be related 
to relative decrements in HDL-C versus increments of LDL-C which coordinate with the assessed increments of MDA herein.

Consistently, the present findings of increased MDA, $\mathrm{H}_{2} \mathrm{O}_{2}$ versus decreased TAC reflecting obesityinduced ROS generation align with the inverse relationship which is reported to exist between the effect of supplied dietary antioxidants and gene expression of NF-K B and IL-1 receptor-1, IL-6 and TNF- ${ }^{(40)}$. Also, it was reported that $\mathrm{H}_{2} \mathrm{O}_{2}$ is raised in adipose tissue as major producer of ROS which coincide with assessed increments of $\mathrm{H}_{2} \mathrm{O}_{2}$ herein ${ }^{(41)}$.

Consistently, the assessed increments of $\mathrm{H}_{2} \mathrm{O}_{2}$ in HFD-rats herein agrees with reports identifying that insulin signaling is inhibited by micromole concentration of $\mathrm{H}_{2} \mathrm{O}_{2}$ which provides evidence for a role of $\mathrm{H}_{2} \mathrm{O}_{2}$ in TNF- $\alpha$ mediated insulin resistance ${ }^{(\mathbf{4 2})}$. It is confirmed herein by development of hepatic steatosis in parallel to increased level of $\mathrm{H}_{2} \mathrm{O}_{2}$ besides MDA as a representation of RONS-induced lipid peroxidation ${ }^{(43) .}$

The assessment herein of reduced levels of TAC has been assumed as a useful tool to monitor the relationship between the HFD-induced obesity and ROS generation which aligns with cumulative supplement of antioxidant food capacity reported to influence several chronic disorders ${ }^{(44)}$.

In addition, the present data aligns with reports identifying independent and inverse relationships of lipooxidizability influencing oxLDL concentrations with dietary and plasma TAC. This could suggest a putative role of an antioxidant rich supplement in the link between minimizing the redox state and retarding development of hepatic steatosis in HFD-induced obesity ${ }^{(40)}$. It is confirmed by the beneficial outcome of porpoise oil supplementation prior to induction of HFD to rats relative to results monitored after induction of HFD and induction of hepatic steatosis ${ }^{(45)}$.

In alignment with the magnitude of ROS generation, the dyslipidemic pattern assessed herein which displayed increased plasma levels of TAG, TC, LDL-c and decreased HDL-c levels coordinated with HFDinduced obesity alongside reduced TAC which potentiated the development of hepatic steatosis ${ }^{(46)}$.

In relevance, the increased ROS production could result from overfeeding with nutrients of an energy dense carbohydrate or lipid rich meal. In response to HFD, an acute period of hyperglycemia or hyperlipidemia may occur inducing postprandial increases in blood glucose or TAG, respectively displaying cardiovascular risk ${ }^{(53)}$.This large influx of substrate (glucose and/ or TAG) in systemic circulation and subsequent processing via the electron transport chain appears to result in the increase in mitochondrial superoxide production from vascular endothelial cells such as an aspect may be implicated in HFD-induced obesity herein ${ }^{\text {(28) }}$

Accordingly, the conjoint development of hepatic steatosis with the alterations monitored in lipid metabolism potentiated by ROS herein could lead to distinct activation of vascular xanthine oxidase (XO) similar to that noted elsewhere ${ }^{(\mathbf{4 8})}$. Thereby, the co-joint pattern of 
increased $\mathrm{XO}$ and $\mathrm{H}_{2} \mathrm{O}_{2}$ herein includes the role of several oxidases e.g. glycolate and xanthine oxidase which occurs in response to HFD.

Hence, as $\mathrm{XO}$ is a ubiquitous free radicals generator leading to superoxide radical, it is also reflective of declining antioxidant defense. Conversely, readjustment of these alterations by porpoise oil supplementation was evaluated herein $^{(49)}$.

It has been reported that ROS production increases in parallel with fat accumulation in adipocytes and that NADPH oxidase is the major source of ROS in adipocytes. Also, in cultured vascular cells, free fatty acid increases NADPH oxidase activity ${ }^{(50)}$. Taken together, these results indicate that increased ROS product in accumulated fat with HFD may be due to activated NADPH oxidase pathway and impaired antioxidant defense ${ }^{(51)}$.

Concordantly, the beneficial impact of porpoise oil supplementation was evident in HFD rats regarding the counteraction of reduced TAC, versus increased $\mathrm{H}_{2} \mathrm{O}_{2}$ as well as the monitored increments of XO generating the superoxide anion by catalyzing the oxidation of hypoxanthine to xanthine furthermore to uric acid ${ }^{(\mathbf{5 2})}$. It reflected the efficacy of porpoise oil supplement to readjust the increments of $\mathrm{XO}$ via exacerbated XO-mediated superoxide production which was induced by obesity status $^{(8)}$.

Collectively, it is evident that following porpoise oil supplement, there was a relative improvement of hyperlipidemic status, and lipid peroxidation alongside substantiation of antioxidative defense ${ }^{(\mathbf{1 7}) .}$ It appeared to be potentiated via antioxidant enzymatic and nonenzymatic mechanisms which counteracted disease development by the increased oxidative stress in accumulated fat ${ }^{(53)}$.

Thus, as noted elsewhere, porpoise oil may lead to increased production of adiponectin whose levels are known to decrease with obesity and increase with weight reduction $^{(54)}$. Its association with free fatty acid release from visceral fat to liver involves fatty acid oxidation/gluconeogenesis

mechanisms influencing glucose homeostasis, energy balance and inflammation (55). This indicates increased proinflammatory cytokine production participating in assessed increments of MDA, LDL-C, TAG, $\mathrm{TC}$, versus decrements of HDL-C and TAC as confirmed herein ${ }^{(56)}$.

Nonetheless, the monitored hypolipidemic effect initiated by porpoise oil application to HFD-rats may involve both reduction of hepatic VLDL-TAG synthesis and secretion and enhancement of TAG clearance from chylomicrons and VLDL particles ${ }^{(38)}$. It may be related to the PUFA constituents of porpoise oil which could pertain a protective antiinflammatory role and indirectly an antioxidant role favoring physiological defense against obesityinduced HFD oxidative stress ${ }^{(57)}$.

Accordingly, based on the monitored histopathological findings herein, it could be suggested that porpoise oil supplementation could prevent the development of fatty liver disease in obesity induced HFD rats ${ }^{(57)}$. It includes multifactorial mechanisms which may occur via the 
enhancement of lipoprotein secretion coinciding with the associated increased HDL-C and adiponectin production $^{(37)}$. Furthermore, the cojoint validity of antioxidant role of porpoise oil relevant to its constitution of lipid lowering effects of $\omega-3$ PUFAs beside its indirect action as antioxidant was evident ${ }^{\text {(57) }}$.

It may reflect the role of the $\omega-3$ PUFA that is one of the active constituents of porpoise oil which is known to be associated with decrease in transcription factors that control the expression of the enzyme responsible for TAG assembly within hepatocytes and responsible for fatty acid oxidation ${ }^{(17)}$

The interplay between the mutual role of $\omega$-3PUFAs and adiponectin in porpoise oil reduction of plasma TAG increments assessed in obesity induced HFD-rats was verified by the associated increments of TAC and anti-inflammatory influence of porpoise oil verified by histopathological findings of hepatosteatosis $^{(\mathbf{1 7}) \text {. }}$

This could be interlinked to the histopathological finding implicating alleviation of hepatic steatosis in parallel to the monitored decreased plasma TAG, LDL-C, TC and increased HDL-C herein ${ }^{(59)}$. This outcome of both antioxidant and antiinflammatory co-linked potency of porpoise oil proved to be beneficial as a natural remedy to obesity induced immune dysregulation and immuneinflammatory disposition ${ }^{(\mathbf{1 7}) .}$

This response to porpoise oil impact potentiating production and activity of adiponectin was verified herein by the co-joint change monitored in both $\mathrm{XO}$ and $\mathrm{H}_{2} \mathrm{O}_{2}$ levels in parallel to TAC and MDA with suppression of hyperlipidemia ${ }^{(17)}$. Moreover, it may be relevant to the other active constituents of porpoise oil including both forms of TAG and phospholipids as well as appreciable amounts of the iso-C5:0valeric acid which can be accommodated in porpoise phospholipids ${ }^{(60)}$.

Hence, the phospholipid components are composed of hydrophobic fatty acids and the hydrophilic moiety choline, ethanolamine, serine or inositol, it is also possible that $\omega$-3PUFAs (in porpoise oil) could enhance the lipidlowering activity of phosphatidylcholine in the liver of obese rats, in addition to reducing NADPH oxidase and inducible nitric oxide synthase (iNOS) activities ${ }^{(61)}$. This represents the anti-inflammatory effects of $\omega$-3PUFAs besides its role in metabolic correction by reducing blood lipids and blood glucose which may altogether contribute to the antioxidative properties as well ${ }^{\mathbf{6 2})}$.

It was reported that serum adiponectin levels were significantly increased by porpoise oil feeding to obese rats, having protective effects against fatty liver diseases through enhancement of lipoprotein synthesis and secretion in rats ${ }^{(63)}$. Furthermore, the present study reflected the beneficial effect of porpoise oil supplement prior to HFD induction of obesity which decelerated free radical generation and progression of OS induced hyperlipidemia influencing immunoinflammatory mechanisms ${ }^{(64)}$.

Porpoise oil in HFD-rats, by lowering the assessed incremental levels of TC, $\mathrm{H}_{2} \mathrm{O}_{2}, \mathrm{XO}$ and MDA, it could reduce the increased production 
of hydroxyl radicals which was noted to extract an electron from polyunsaturated lipids generating high oxygen producing lipid peroxyl radicals and $\mathrm{LOOH}^{(65)}$.

Conclusion: On the basis of these results it could be concluded that obesity is a state of chronic oxidative stress and may be an inductive factor of several biochemical, metabolic alterations and also hepatic histopathological changes. Porpoise oil significantly improves the biochemical, metabolic and histopathological abnormalities induced by obesity due to its powerful lipid lowering and anti-inflammatory effects and unique antioxidant properties.

Recommendation: Porpoise oil is recommended to be prescribed as a co- therapy for obesity.

\section{REFERENCES}

1. Haslam DW and James WP (2005): Obesity. Lancet 366 (9492): 1197-1209.

2. Von Diemen V, Trindade EN, Trindade MR. (2006): Experimental model to induce obesity in rats. Acta Cir. Bras., 21(6):425-9. Review

3. Fabbrini E, Sullivan S, Klein S. (2010): Obesity and nonalcoholic fatty liver disease: biochemical, metabolic, and clinical implications. Hepatology 51(2): 679-89.

4. Postic C, Girard J. (2008): Contribution of de novo fatty acid synthesis to hepatic steatosis and insulin resistance: lessons from genetically engineered mice. J. Clin. Invest., 118(3):829-38.
5. Rhoads DM, Umbach AL, Subbaiah CC, Siedow JN. (2006): Mitochondrial reactive oxygen species: Contribution to oxidative stress and interorganellar signaling. Plant Physiol., 141(2):357-366

6. Fernández-Sánchez A, Madrigal-Santillán E, Bautista M, Esquivel-Soto J, MoralesGonzález A, Esquivel-Chirino C, Durante-Montiel I, SánchezRivera G, Valadez-Vega C, Morales-González JA. (2011): Inflammation, oxidative stress, and obesity. Int. J. Mol. Sci., 12(5):3117-32.

7. Nishino $T$, Okamoto $K$, Eger BT, Pai EF, Nishino T. (2008): Mammalian xanthine oxidoreductase - mechanism of transition from xanthine dehydrogenase to xanthine oxidase. FEBS J., 275(13):327889.

8. Metz S and Thiel W. (2009): A combined QM/MM Study on the reductive half-reaction of xanthine oxidase: Substrate orientation and mechanism. J. Am. Chem. Soc., 131 (41): 14885-14902.

9. Hille $R$ (2005): Molybdenumcontaining hydroxylases. Arch. Biochem. Biophys., 433 (1): 10716.

10. Bloomer RJ and FisherWellman KH (2009): Systemic oxidative stress is increased to a greater degree in young obese women following consumption of a high fat meal. Oxid. Med. Cell. Long., 2 (1): 19-25.

11. Trachootham D, Lu W, Ogasawara MA, Nilsa RD, 
Huang P. (2008): Redox regulation of cell survival. Antioxid. Redox Signal., 10(8): 1343-74.

12. Circu ML, Aw TY. (2010): Reactive oxygen species, cellular redox systems, and apoptosis. Free Radic. Biol. Med., 48(6):749-62.

13. Grotto D; Maria LS; Valentini J; Paniz C; Schmitt G; Garcia SC; Pomblum VJ; Rocha JBT; Farina $M$ (2009): Importance of lipid peroxidation biomarkers and methodological aspects for malondialdehyde quantification. Quim. Nova 32:169-174.

14. Folden DV, Gupta A, Sharma AC, Li SY, Saari JT, Ren J.. (2003): Malondialdehyde inhibits cardiac contractile function in ventricular myocytes via a p38 mitogen-activated protein kinasedependent mechanism. British J. of Pharmacology 139(7): 13101316.

15. Amirkhizi F, Siassi F, Djalali $M$ and Foroushanic AR (2010): Evaluation of oxidative stress and total antioxidant capacity in women with general and abdominal adiposity. Obesity Research \& Clinical Practice 4(3): 209-216.

16. Suresh DR, Annam V, Pratibha K, Prasad BVM. (2009): Total antioxidant capacity--a novel early bio-chemical marker of oxidative stress in HIV infected individuals. J. Biomed. Sci., 16(1):61.

17. Shirouchi B, Nagao K, Furuya K, Nagai T, Ichioka $\mathbf{K}$, Tokairin S, Iida Y, Yanagita T (2010): Physiological functions of iso-type short chain fatty acid omega 3 polyunsaturated fatty acids containing oil in obese OLETF rats. J. Oleo. Sci., 59 (6): 299-305.

18. Celik VK, Sari I, Engin A, Gürsel Y, Aydin H, Bakir S. (2010): Determination of serum adenosine deaminase and xanthine oxidase levels in patients with crimean-congo hemorrhagic fever. Clinics (Sao Paulo) 65(7):697-702.

19. Koracevic D, Koracevic G, Djordjevic V, Andrejevic S, Cosic V. (2001): Method for the measurement of antioxidant activity in human fluids J. Clin. Pathol., 54(5): 356-361.

20. Fossati $P$, Prencipe $L$ and Berti G (1980): Use of 3,5-dichloro-2hydroxybenzenesulfonic acid/4aminophenazone chromogenic system in direct enzymic assay of uric acid in serum and urine. Clin. Chem., 26(2):227-31.

21. Satoh K (1978): Serum lipid peroxide in cerebrovascular disorders determined by a new colorimetric method. Clinica Chimica. Acta 90(1): 37-43.

22. Ohkawa $H$, Ohishi $N$ and Yagi K (1979): Assay for lipid peroxides in animal tissues by thiobarbituric acid reaction. Anal. Biochem., 95(2): 351-358.

23. Fossati $P$ and Prencipe $L$ (1982): Serum triglycerides determined colorimetrically with an enzyme that produces hydrogen peroxide. Clin. Chem., 28(2): 2077- 2080.

24. Richmond W (1973): Preparation and properties of a cholesterol oxidase from 
Nocardia sp. and its application to the enzymatic assay of total cholesterol in serum. Clin. Chem., 19(12): 1350- 1356.

25. Grove TH (1979): Effect of reagent $\mathrm{pH}$ on determination of HDL cholesterol by precipitation with sodium phosphotungestate magnesium. Clin. Chem., 25(4):560.

26. Friedewald WT, Levy RI and Fredrickson DS (1972): Estimation of the concentration of low-density lipoprotein cholesterol in plasma, without use of the preparative ultracentrifuge. Clin. Chem., 18(6): 499-502.

27. Couillard C, Ruel G, Archer WR, Pomerleau S, Bergeron J, Couture P, Lamarche B, Bergeron N.. (2005): Circulating level of oxidative stress markers and endothelial adhesion molecules in men with abdominal obesity. J. Clin. Endocrinol. Metab., 90(12): 6454-6459.

28. Erdei N, Tóth A, Pásztor ET, Papp Z, Edes I, Koller A, Bagi Z. (2006): High-fat dietinduced reduction in nitric oxidedependent arteriolar dilation in rats: role of xanthine oxidasederived superoxide anion. Am. J. Physiol. Heart Circ. Physiol., 291(5):H2107-2115.

29. Lechleitner M, Koch T, Herold M, Dzien A, Hoppichler F. (2000): Tumor necrosis factoralpha plasma level in patients with type 1 diabetes mellitus and its association with glycemic control and cardiovascular risk factors. J. Intern. Med., 248(1) :67-76.
30. Demori I, Voci A, Fugassa E and Burlando $B$ (2006): Combined effects of high-fat diet and ethanol induce oxidative stress in rat liver. Alcohol 40(3):185-185.

31. Wang $S$, Wu D, Lamon-Fava $S$, Matthan NR, Honda KL and Lichtenstein AH (2009): In vitro fatty acid enrichment of macrophages alters inflammatory response and net cholesterol accumulation. Br. J. Nutr., 102(4):497-501.

32. Amirkhizi F, Siassi F, Minaie S, Djalali $M$, Rahimi $A$ and Chamari M (2007): Is obesity associated with increased plasma lipid peroxidation and oxidative stress in women. ARYA Atherosclerosis J., 2(4):189-192.

33. Thomàs-Moyà E, Gómez-Pérez Y, Fiol M, Gianotti M, Lladó I, Proenza AM. (2008): Gender related differences in paraoxonase 1 response to high-fat diet induced oxidative stress. Obesity 16(10):2232-2238.

34. Nagao K.,Inoue N, Wang YM., Shirouchi $B$ and Yangita $T$ (2005): Dietary conjugated linoleic acid alleviates nonalcoholic fatty liver disease in Zucker (fa/fa) rats. J. Nutr., 135(1): 9-13.

35. Lin E, Phillips LS, Ziegler TR, Schmotzer B, Wu K, Gu LH, Khaitan L, Lynch SA, Torres WE, Smith CD, GletsuMiller N. (2007): Increases in adiponectin predict improved liver, but not peripheral, insulin sensitivity in severely obese women during weight loss. Diabetes 56(3):735-42. 
36. Manea A (2010): NADPH oxidase-derived reactive oxygen species: involvement in vascular physiology and pathology. Cell Tissue Res., 342(3):325-39.

37. Amirkhizia F, Siassi F, Djalali $M$ and Shahraki SH (2012): Impaired enzymatic antioxidant defense in erythrocytes of women with general and abdominal obesity. Obesity Research \& Clinical Practice 3: 1-9.

38. Limón-Pacheco J, Gonsebatt ME (2009): The role of antioxidants and antioxidantrelated enzymes in protective responses to environmentally induced oxidative stress. Mutat. Res., 674(1-2):137-47.

39. Norris AL, Steinberger J, Steffen LM, Metzig AM, Schwarzenberg SJ, Kelly AS., (2011): Circulating oxidized LDL and inflammation in extreme pediatric obesity. Obesity 19(7):1415-9.

40. Hermsdorff HH, Zulet MA, Puchau B, Martínez JA. (2010): Fruit and vegetable consumption and proinflammatory gene expression from peripheral blood mononuclear cells in young adults: a translational study. Nutrition \& Metabolism (London) 7:42.

41. Okada S, Kozuka C, Masuzaki H, Yasue S, Ishii-Yonemoto T, Tanaka T, Yamamoto $Y$, Noguchi M, Kusakabe T, Tomita T, Fujikura J, Ebihara $\mathbf{K}$, Hosoda $\mathbf{K}$, Sakaue $\mathbf{H}$, Kobori H, Ham M, Lee YS, Kim JB, Saito Y, Nakao K. (2010): Adipose tissue-specific dysregulation of angiotensinogen by oxidative stress in obesity. Metabolism 59(9):1241-51.

42. Hansen LL, Ikeda Y, Olsen GS, Busch AK, Mosthaf L. (1999): Insulin signaling is inhibited by micromolar concentrations of $\mathrm{H}_{2} \mathrm{O}_{2}$ : evidence for a role of $\mathrm{H}_{2} \mathrm{O}_{2}$ in tumor necrosis factor alpha-mediated insulin resistance. J. Biol. Chem., 274(35): 25078-84.

43. Sinha-Hikim I, Sinha-Hikim AP, Shen R, Kim HJ, French SW, Vaziri ND, Crum AC, Rajavashisth TB, Norris KC (2011): novel cystine based antioxidant attenuates oxidative stress and hepatic steatosis in diet-induced obese mice. Exper. Molec. Pathol., 91(1): 419-428.

44. Dahiya P, Kamal R, Gupta R(2012): Obesity, periodontal and general health: relationship and management. Indian $\mathrm{J}$. Endocrinology and metabolism 16(1): 88-93.

45. Roberts RA, Smith RA, Safe S, Szabo C, Tjalkens RB, Robertson FM. (2010): Toxicological and pathophysiological roles of reactive oxygen and nitrogen species. Toxicology 276(2):8594.

46. Karaouzene N, Merzouk H, Aribi M, Merzouk SA, Berrouiguet AY, Tessier C, Narce M. (2011): Effects of the association of aging and obesity on lipids, lipoproteins and oxidative stress biomarkers: A comparison of older with young men. Nut., Metab. Cardiovasc. Dis., 21(10): 792-799. 
47. Leopold JA and Loscalzo J (2008): Oxidative mechanisms and atherothrombotic cardiovascular disease. Drug Discov. Today Ther Strateg., 5(1): 5-13.

48. Bedard $K$ and Krause $K H$ (2007): The NOX family of ROSgenerating NADPH oxidases: physiology and pathophysiology. Physiol. Rev., 87(1):245-313.

49. Dalle-Donne I, Rossi R, Colombo R, Giustarini $D$ and Milzani A (2006): Biomarkers of oxidative damage in human disease. Clin. Chem., 52(4):60123.

50. Lyon CJ, Law RE and Hsueh WA (2003): Minireview: adiposity, inflammation, and atherogenesis. Endocrinology 144(6): 2195-2200.

51. Furukawa $S$, Fujita $T$, Shimabukuro M, Iwaki M, Yamada Y, Nakajima Y, Nakayama O, Makishima M, Matsuda M, Shimomura I. (2004): Increased oxidative stress in obesity and its impact on metabolic syndrome. J. Clin. Invest., 114(12):1752-1761.

52. Sautin YY, Nakagawa $T$, Zharikov $S$ and Johnson RJ (2007): Adverse effects of the classic antioxidant uric acid in adipocytes: NADPH oxidasemediated oxidative/nitrosative stress. Am. J. Physiol. Cell Physiol. 293(2): C584e96.

53. Hajer GR, van Haeften TW, Visseren FL (2008): Adipose tissue dysfunction in obesity, diabetes, and vascular diseases. Eur. Heart J., 29(24):2959-2971.
54. Milan G, Granzotto $M$, Scarda A, Calcagno A, Pagano C, Federspil G, Vettor R. (2002): Resistin and adiponectin expression in visceral fat of obese rats: effect of weight loss. Obes. Res., 10(11):1095-103.

55. Vaiopoulos AG, Marinou K, Christodoulides C, Koutsilieris M. (2012): The role of adiponectin in human vascular physiology. Int. J. Cardiol., 155 (2): 188-193.

56. Park HS, Park JY and Yu R (2005): Relationship of obesity and visceral adiposity with serum concentrations of CRP, TNFalpha and IL-6. Diabetes Res. Clin. Pract., 69(1):29-35.

57. Lee LK, Shahar S, Rajab N, Yusoff NA, Jamal RA, Then SM. (2012): The role of long chain omega-3 polyunsaturated fatty acids in reducing lipid peroxidation among elderly patients with mild cognitive impairment: a case-control study. Journal of Nutritional Biochemistry 2: 30-33.

58. Pachikian BD, Essaghir A, Demoulin JB, Neyrinck AM, Catry E, De Backer FC, Dejeans N, Dewulf EM,Sohet FM, Portois L, Deldicque $\mathbf{L}$, Molendi-Coste O, Leclercq IA, Francaux M, Carpentier YA, Foufelle F,Muccioli GG, Cani PD, Delzenne NM. (2011): hepatic n-3 polyunsaturated fatty acid depletion promotes steatosis and insulin resistance in mice: genomic analysis of cellular targets. PLoS ONE 6(8): e23365.

59. Tomita K, Oike Y, Teratani T, Taguchi T, Noguchi M, Suzuki 
T, Mizutani A, Yokoyama H, Irie $\quad R$, Sumimoto $H$, Takayanagi A, Miyashita K, Akao M, Tabata M, Tamiya G, Ohkura T, Hibi T. (2008): Hepatic AdipoR2 signaling plays a protective role against progression of nonalcoholic steatohepatitis in mice. Hepatology 48(2):458-73.

60. Terbach $\mathbf{N}$ and Williams RS (2009): structure function studies for the panacea, valproic acid. Biochem. Soc. Trans,. 37(Pt.5): 1126-1132.

61. Shirouchi B; Nagao K; Inoue N; Furuya K; Koga S, Matsumoto $H$, and Yanagita, $T$ (2008): Dietary phosphatidylinositol prevents the development of nonalcoholic fatty liver disease in Zucker rats. J. Agric. Food Chem., 56(7): 2375-79.

62. Poudyal H, Panchal SK, Diwan V, Brown L. (2011): Omega-3 fatty acids and metabolic syndrome: Effects and emerging mechanisms of action. Progress in Lipid Research 50(4): 372-387.

63. Rodríguez-Mañas L, Angulo J, Vallejo S, Peiró C, SánchezFerrer A, Cercas E, LópezDóriga $P$, Sánchez-Ferrer CF. (2003): Early and intermediate Amadori glycosylation adducts, oxidative stress, and endothelial dysfunction in the streptozotocininduced diabetic rats vasculature. Diabetologia 46(4): 556-566.

64. Shirouchi, B.; Nagao, K.; Inoue, N.;Ohkubo, T. Hibino, $H$ and Yanagita T. (2007): Effect of dietary omega 3 phosphatidylcholine on obesity- related disorders in obese Ostuka Long Evans Tokushima fatty rats. J. Agric. Food Chem,, 55(17): 7170-76.

65. Niki E (2010): Assessment of antioxidant capacity in vitro and in vivo. Free Rad. Biol. Med., 49(4): 503-15.

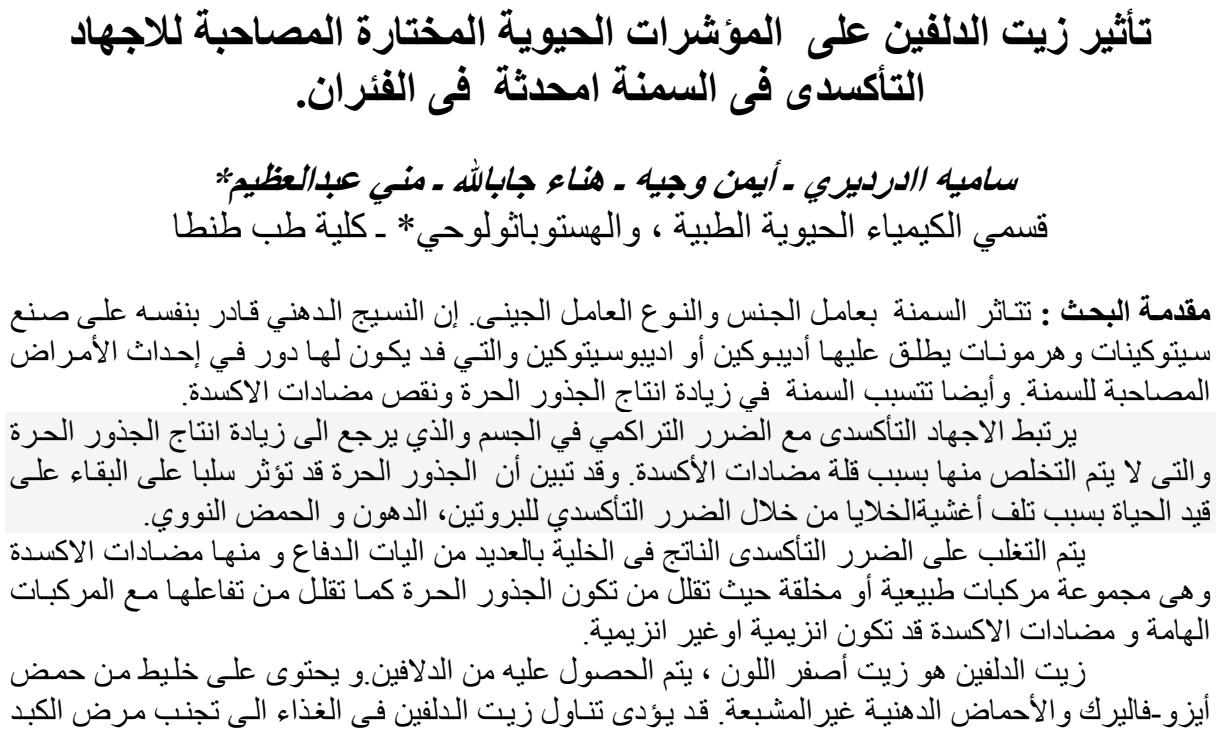




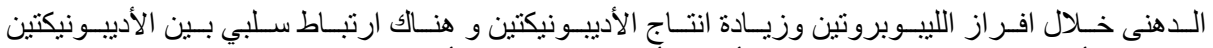

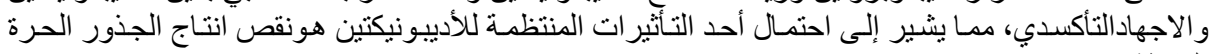
النشطة

الهدف من البحث: يهدف البحث إلى إلقاء الضوء على على الاليات المصـاحبة للاقلال من الاجهاد التاكسدى الناتج

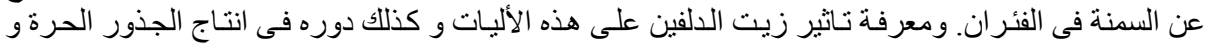
مقاومة السمنة المسببة لزيادة الدهون في الجسم.

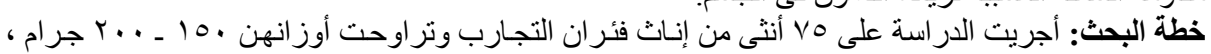

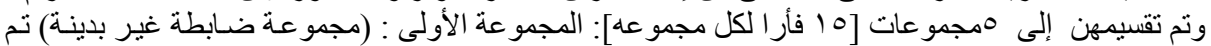

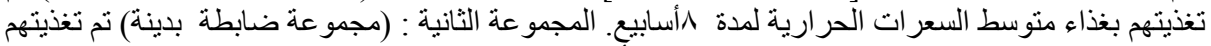

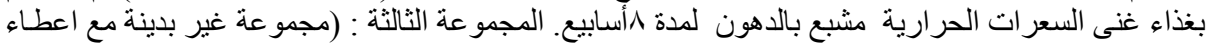

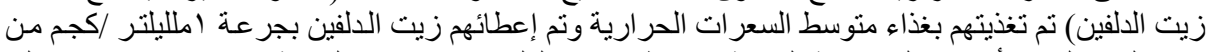

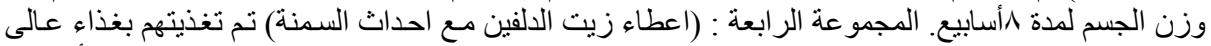

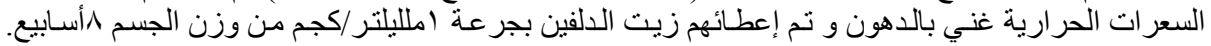

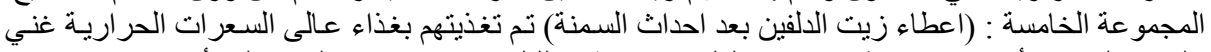

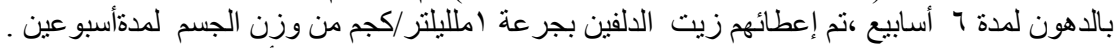

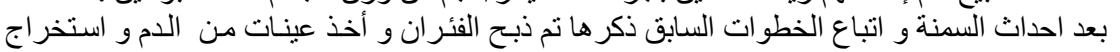

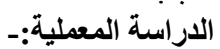

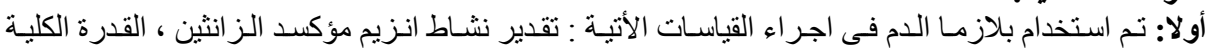

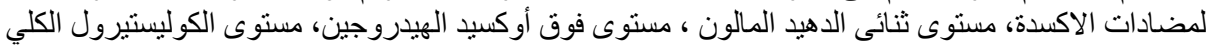

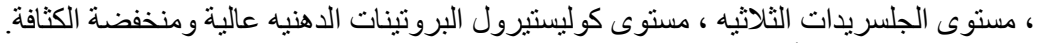

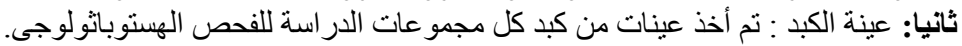
وقد أوضحت الإر اسة النتائج الآتية:

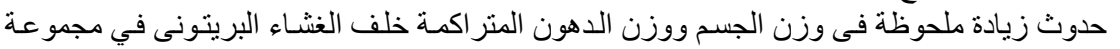

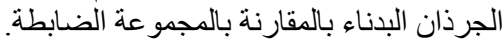

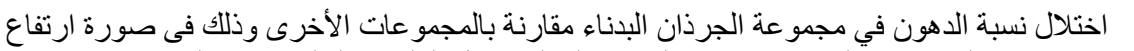

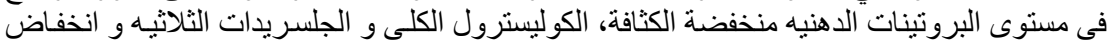

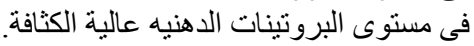

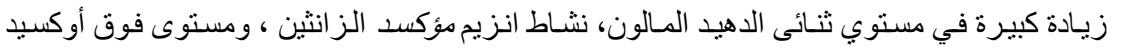

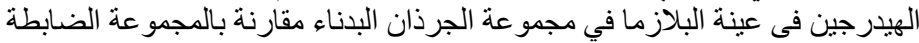

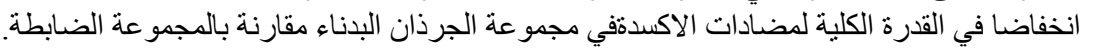

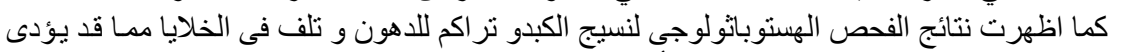

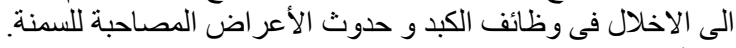

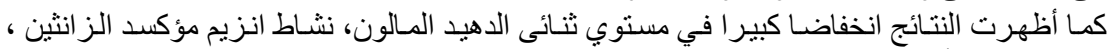

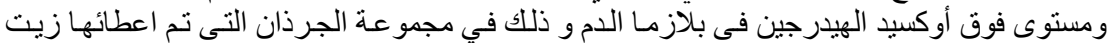
الدلفين مقارنة بالمجمو عة البونة البدينة.

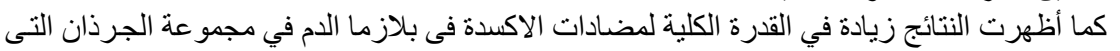

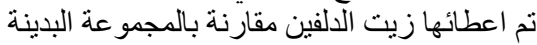

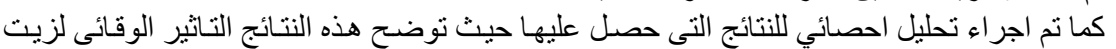
الدلفين في الأمر اض الناتجة عن السمنة وخاصة الكبد النبد الدهني. 